15. Lowry, O. H Rosebrough, N. J., Farr A. L and Randall, R. G.: Protein measurement with the folin phenol reagent. J. Biol. Chem., 193: 265 (1951).

16. McDonald, N. M., Bruns, D. E., and Jarett, L.: Characterization of calcium binding to adipocyte plasma membrane. J. Biol. Chem., 25I: 1354 (1976).

17. Melcher, D. L. and Steim, J. M.: Thermotropic transitions in biomembranes. Ann. Rev. Biophys. Bioeng., 5: 205 (1976)

18. Messer, M. and Dahlquist, A.: A one step ultramicromethod for the assay of intestinal dissacharidases, Anal. Biochem. 14:376 (1966).

19. Nicholson, G. L., Poste, G., and The, J.: Dynamic aspects of cell surface organization. Ed: G. Poste and G. Nicholson. pp. 1-73 (North Holland, Amsterdam 1971).

20. Nuston, C., Pangborn, W., Nir, Z., and Papadjopoulos, D.: Specificity of $\mathrm{Ca}^{++}$ and $\mathrm{Mg}^{++}$binding to phosphatidyl serine vesicles and resultant phase changes of biliary in membrane structure. Biochem. Biophys. Acta, 506: 281 (1978).

21. Palmer, R. F. and Posey, V. A.: Calcium and adenosine triphosphate binding to renal membranes. J. Gen. Physiol., 55: 89 (1970).

22. Pang, K. Y., Bresson, J. L., and Walker, W. A.: Development of the gastrointestinal barrier III. Evidence for structural differences in microvillus membrane from newborn and adult rabbits. Biochim. Biophys. Acta, 727: 201 (1983).

23. Sauerheber, R. D., Lewis, U. J., Esgate, G. A., and Gordon, L. M.: Effect of calcium insulin and growth hormone on membrane fluidity. A spin label study of rat adipocyte and human erythrocyte ghosts. Biochem. Biophys. Acta, 597: 294 (1980).

24. Scatchard, G.: Attractions of proteins for small molecules and ions. Ann. N Y. Acad. Sci.. 51: 660 (1949).

25. Schmitz, G., Preizer, H., Malstracci, D., Ghost, B. K., Cerda, J. G., and Crane, R. K.: Purification of the human intestinal brush border membrane. Biochim. Biophys. Acta, 323: 98 (1973).

26. Schwarz, S. M., Hostetler, B., Ling, E., Lel, L., and Walkins, G. B.: Fluorescence polarization studies of the small intestinal microvillus membrane during development. Gastroenterology, 82: 1176 (1982).

27. Schlatz, L and Marinetti, G. V.: Calcium binding to the rat liver plasma membrane. Biochim. Biophys. Acta, 290: 70 (1972).

28. Tsuboi, K. K., Schwartz, S. M., Burrill, P. H., Kwong. L. K., and Sunshine, P.: Sugar hydrolysis of the infant rat intestine and their arrangement of the brush border membrane. Biochim. Biophys. Acta, 554: 234 (1979).

29. Udall, N. J. Pang K. Fritze, L. Kleinman, R. and Walker, W. A - Development of gastrointestinal mucosal barrier. $I$. The effect of age on intestinal permeability to macromolecules. Pediat. Res., 15: 241 (1981).

30. Udall, J. N., Colony, P., Fritze, L., Pang, K., Trier, J. S. and Walker, W. A.: Development of gastrointestinal mucosal barrier. The effect of natural versus artificial feedings on intestinal permeability to macromolecules. Pediatr. Res., 15: 245 (1981).

31. Walker, W. A., Cornell, R., Davenport, L. M. and Isselbacher, K. G.: Macromolecules absorption: Mechanism of horseradish peroxidase uptake and transport in adult and neonatal rat intestine. J. Cell Biol., 54: 195 (1972).

32. Warshaw, A. L., Walker, W. A., Cornell, R. and Isselbacher, K. J.: Small intestine permeability to macromolecules: Transmission of horseradish peroxidase into mesenteric lympyh and portal blood. Lab. Invest., 26: 675 (1971).

33. Current address: Department de Pediatrie, Hopital des Enfants Malades, Paris, France.

34. Received for publication Dr. Kam-Yee Pang, Pediatric Gastrointestinal and Nutrition Unit, Massachusetts General Hospital, Boston, MA 02114.

35. Supported by research grants from the National Institute of Health (AM 16269 HDI 2437 and GM21700) Dr. Pang is a trainee in Gastrointestinal Research (T32-AM0791)

36. Received for publication August 26, 1982

37. Accepted for publication March 23, 1983.

\title{
The Diagnosis and Staging of Hypocortisolism in Progressing Autoimmune Adrenalitis
}

\author{
SEPPO LEISTI, ${ }^{(32)}$ PEKKA AHONEN, AND JAAKKO PERHEENTUPA \\ The Children's Hospital, University of Helsinki, Helsinki, Finland
}

\section{Summary}

The course of development of hypocortisolism was studied in 20 patients with autoimmune polyendocrinopathy-candidosis-ectodermal dystrophy (APECED) for 1.3-9.3 years during which time the patients underwent at least three 2-h ACTH tests $(2 \mathrm{hAT})$. A slow progression of the disease was evident and could be staged. The earliest indicators of incipient failure were subnormality of the 2 -h cortisol level alone or with subnormality of the 2-h increment. The increment was then abolished. A normal basal level was maintained longer. Longer forms of the ACTH tests produced normal responses even after the early stages of failure. A constantly elevated ACTH concentration and low cortisol/ACTH ratio in plasma were likewise signs of advanced hypocortisolism. Current criteria of primary hypocortisolism are thus indicators of the late stages of failure only. The presence of circulating adrenocortical antibodies is predictive of hypocortisolism. Some patients had normal $2 \mathrm{hAT}$ responses, but antibodies and subnormal cortisol/ACTH ratios. This may represent a state of compensatory activation of the hypothalamic-pituitaryadrenocortical axis.

\section{Abbreviations}

APECED, autoimmune polyendocrinopathy-candidosis-ectodermal dystrophy
4dAT, 4-day ACTH test 2hAT, 2-h ACTH test 17-OGS, 17 oxogenic steroids RIA, radioimmunoassay

Autoimmune adrenalitis is a major cause of Addison's disease. In patients with polyendocrine deficiency diseases and their siblings, frequent testing of cortisol reserve is essential for early detection of failure of cortisol secretory capacity. Long lasting ACTH tests are impractical, because they entail hospitalization. Furthermore, such tests may not be sensitive enough to detect incipient failure. To our knowledge, no systematic study has appeared on the progression of hypocortisolism in adrenalitis. Neither have criteria been established for early stages of primary hypocortisolism. Such criteria would be important for the safety of individuals at risk. We have used an ambulatory 2-h ACTH test (2hAT) (13) for both detection and follow-up of progression of hypocortisolism in our large series of patients with APECED $(18,23)$. The $2 \mathrm{hAT}$ was clearly more sensitive than the $4 \mathrm{dAT}$ for the detection of incipient failure and even more sensitive than determinations of plasma ACTH. Our experience with these patients calls for a revision of the current diagnostic criteria of Addison's disease. 


\section{SUBJECTS AND METHODS}

Of a total of 40 patients with APECED managed by us in 1970-1980 (23), 20 are the subjects of this report (Table 1). All patients included in this study had been followed for at least 1 year and with a minimum of three $2 \mathrm{hATs}$. The median interval between tests was 0.8 (range, $0.1-3.3$ ) years. At the start of the follow-up none of the 20 patients was substituted for cortisol and 17 of them had normal adrenocortical function. The diagnosis of APECED was based on the presence of at least two of the following features (or one if a sib had at least two): mucocutaneous candidosis, hypoparathyroidism, hypoadrenocorticism, and ectodermal dystrophy $(19,23)$ (enamel hypoplasia, onychia punctata). Fourteen of the patients had circulating adrenocortical antibodies. A group of twenty-five children with hypopituitarism including ACTH deficiency were also given a total of $342 \mathrm{hATs}$ to allow comparison of the results during primary and secondary hypocortisolism. The diagnosis of ACTH deficiency was based on subnormal plasma cortisol response to at least two insulin tests. Most patients also had metyrapone tests, always with a subnormal response. Of the hypopituitary patients, 18 had a hypothalamic tumor, four had been born in breech presentation, one had sequelae of subdural effusion, and two cases were idiopathic.

Cortisol substitution was given as oral cortisol, $7.5-10 \mathrm{mg}$ daily divided in three doses. This substitution was stopped on the day preceding the test and resumed upon completion of the test. Adequate substitution therapy was given for any associated endocrine deficiencies. Aldosterone deficiency was substituted for by $9 \alpha$-fluorocortisol, $0.025-0.1 \mathrm{mg}$ daily, in salt-losing patients. The development of mineralocorticoid deficiency will be the subject of another report. Informed consent was obtained before testing the patients.

The 2 hAT (13), the insulin test (14), and the vasopressin test (15) were performed as previously described. For the $4 \mathrm{dAT}$, the patient was hospitalized in order to collect four consecutive 24h urines for determination of 17-OGS. On days 2,3 , and $4, \mathrm{Zn}$ $\mathrm{ACTH}_{1-24}$ (S-Cortrophin depot, Organon, Netherlands) $1.0 \mathrm{mg} /$ $1.73 \mathrm{~m}^{2}$ was given intramuscularly at $8 \mathrm{a} . \mathrm{m}$. An increment of $35 \%$ from the basal $17-O G S$ indicated a significant response (12).
A $2 \mathrm{hAT}$ performed on the morning after the $4 \mathrm{dAT}$ is called a primed $2 \mathrm{hAT}$. The result of this test was compared with the result of a $2 \mathrm{hAT}$ given on the morning before a $4 \mathrm{dAT}$.

Laboratory methods. Plasma 11-hydroxycorticoids (hereafter referred to as a cortisol) were determined by a two-point fluorometry method (13) with a between-assay coefficient of variation of $<5.4 \%$ for levels between $15-72 \mu \mathrm{g} / \mathrm{dl}(0.47-2.0 \mu \mathrm{M})$. The precision of the method was strictly controlled and the method was unchanged during the period of this study. Its accuracy was evaluated by parallel determination of cortisol with a specific RIA in 34 samples (ranges, $5.4-47 \mu \mathrm{g} / \mathrm{dl}$ by RIA). The correlation was high $(r=0.96)$ with linear regression: cortisol $_{\mathrm{RIA}}=0.75$ cortisol $_{\mathrm{F} 1}+5.7 \mu \mathrm{g} / \mathrm{dl}$. Urinary 17-OGS were determined by colorimetry (30), and reported as $\mathrm{mg} \cdot \mathrm{m}^{-2} \cdot \mathrm{day}^{-1}$. Plasma ACTH was assayed with a radioimmunoassay kit (Sorin, Biomedica, 13040 Saluggia, Vercelli, Italy). Blood samples were chilled on ice water, and plasma was separated without delay. $\mathrm{N}$-methylmaleinimide was added to an $1 \mathrm{mM}$ concentration, and the mixture was stored at $-18^{\circ} \mathrm{C}$ until assayed for $\mathrm{ACTH}$. The limit of sensitivity was $10 \mathrm{ng} / \mathrm{liter}$, and basal levels of $>100 \mathrm{ng} / \mathrm{liter}$ were considered elevated. For anti-adrenocortical antibodies (hereafter referred to as antibodies), sera were tested by an indirect imunofluorescence method (11).

Statistical analysis. Means, S.D.s, and S.E.M.s of endocrine values were calculated from log transformed data; hence, all means are geometric, and S.E.M.s are given as percentages (28). Normal response criteria for the $2 \mathrm{hAT}$ were based on results for 30 healthy children aged 2.8-18.4 years. Because both the 2-h plasma cortisol levels and the 2 -h increments showed a strong inter-individual dependence on the basal level, a normal result is most accurately defined by an area formed on a plot of 2-h level versus basal level by the $95 \%$ confidence limits for the estimation of 2 -h levels for given basal levels, and by the $95 \%$ confidence limits for the basal level $(7-36 \mu \mathrm{g} / \mathrm{dl} ; 0.19-1.00 \mu \mathrm{M})$ (13). An increment of $>3.0$ S.D. of the method variability ( 3 S.D. $=3.0 \mu \mathrm{g} / \mathrm{dl} ; 0.08 \mu \mathrm{M})$ was regarded as significant. The $95 \%$ confidence ranges of the results for the reference populations were used as reference ranges for the other tests. For the 4dAT and the primed $2 \mathrm{hAT}$ the reference populations consisted of patients who had normal results in the $2 \mathrm{hAT}$.

Table 1. Clinical characteristics of 20 patients with APECED followed with the $2 h A T$

\begin{tabular}{|c|c|c|c|c|c|c|c|}
\hline Patient & Sex & $\begin{array}{l}\text { Age at start of } \\
\text { follow-up (yr) }\end{array}$ & $\begin{array}{c}\text { Duration of } \\
\text { follow-up (yr) }\end{array}$ & $\begin{array}{l}\text { Stage of cortisol } \\
\text { capacity at start/ } \\
\text { end of follow-up }\end{array}$ & $\begin{array}{l}\text { Age at start of } \\
\text { cortisol/aldosterone } \\
\text { substitution (yr) }\end{array}$ & Antibodies & $\begin{array}{c}\text { Other components } \\
\text { of APECED }\end{array}$ \\
\hline 1 & $\mathrm{~F}$ & 4.4 & 6.6 & $\mathrm{~N} / \mathrm{N}$ & $-1-$ & - & c, $\mathrm{P}$ \\
\hline 2 & $\mathrm{~F}$ & 6.7 & 7.3 & $\mathrm{~N} / \mathrm{N}$ & $-1-$ & - & c. $\mathrm{P}$ \\
\hline 3 & $\mathrm{~F}$ & 11.2 & 7.4 & $\mathrm{~N} / \mathrm{N}$ & $-1-$ & - & c, $\mathrm{P}$ \\
\hline 4 & $\mathrm{M}$ & 16.3 & 6.7 & $\mathrm{~N} / \mathrm{N}$ & $-1-$ & - & $c, P$ \\
\hline 5 & $\mathrm{M}$ & 8.2 & 9.2 & $\mathrm{~N} / \mathrm{sL}$ & $-1-$ & + & c, $\mathrm{P}$ \\
\hline 6 & $\mathrm{~F}$ & 14.1 & 5.4 & $\mathrm{~N} / \mathrm{sL}$ & $-/ 19.2$ & + & $c$ \\
\hline 7 & $\mathrm{M}$ & 13.9 & 3.9 & $\mathrm{~N} / \mathrm{sL}$ & $-1-$ & - & c \\
\hline 8 & $\mathbf{M}$ & 1.9 & 4.5 & $\mathrm{~N} / \mathrm{sLI}$ & $-/ 5.5$ & + & $c, P, D$ \\
\hline 9 & M & 5.0 & 8.5 & $\mathrm{~N} / \mathrm{sLI}$ & $-1-$ & - & $c, P, l$ \\
\hline 10 & $\mathrm{~F}$ & 7.7 & 5.1 & $\mathrm{~N} / \mathrm{sLI}$ & $-1-$ & N.D. & $\mathrm{c}, \mathrm{P}$ \\
\hline 11 & $\mathrm{M}$ & 9.5 & 11.4 & $\mathrm{~N} / \mathrm{sLI}$ & $-1-$ & + & $c, P$ \\
\hline 12 & $\mathrm{M}$ & 11.7 & 3.3 & sLI/sLI & $-/ 10.1$ & + & $\mathrm{c}, \mathrm{P}$ \\
\hline 13 & $\mathrm{~F}$ & 6.1 & 7.9 & N/sLal & $-1-$ & + & $c, P, G$ \\
\hline 14 & $\mathrm{~F}$ & 17.8 & 9.3 & $\mathrm{~N} / \mathrm{sLaI}$ & $-1-$ & + & $c, P, G$ \\
\hline 15 & $\mathrm{~F}$ & 3.6 & 8.6 & $\mathrm{~N} / \mathrm{sLaI}$ & $8.8 / 8.8$ & - & $\mathrm{P}$ \\
\hline 16 & $\mathrm{~F}$ & 5.8 & 7.0 & $\mathrm{~N} / \mathrm{R}$ & $11.6 /-$ & + & $c, P, G, D$ \\
\hline 17 & $\mathrm{~F}$ & 5.9 & 1.3 & $\mathrm{sLl} / \mathrm{R}$ & $6.9 / 5.8$ & + & $\mathrm{c}, \mathrm{P}, \mathrm{G}$ \\
\hline 18 & $\mathrm{M}$ & 8.0 & 7.6 & $\mathrm{~N} / \mathrm{R}$ & $15.0 /-$ & + & $\mathrm{c}, \mathrm{P}$ \\
\hline 19 & $\mathrm{~F}$ & 9.8 & 2.3 & $N / R$ & $11.0 / 12.8$ & + & $\mathrm{c}, \mathrm{P}, \mathrm{G}$ \\
\hline 20 & $\mathrm{~F}$ & 12.3 & 3.2 & sLaI/R & $13.2 / 13.4$ & + & $c, P, G$ \\
\hline
\end{tabular}

' $\mathrm{N}$, normal response in 2hAT; sL, subnormal 2-h cortisol level; sLI, subnormal 2-h-cortisol level with subnormal but significant 2-h increment: sLaI, subnormal level with absent increment; $R$, on cortisol substitution.

${ }^{2}$ c, mucocutaneous candidodis; $P$, hypoparathyroidism; G, gonadal failure; D, diabetes mellitus; and I, intrinsic factor deficiency (ectodermal components not listed). 
Student's $t$ test was used for evaluation of differences between means.

Staging of cortisol secretory capacity. At each evaluation the patients' capacity to secrete cortisol was allocated according to the $2 \mathrm{hAT}$ response and therapy, to one of the following stages of decreasing capacity: Stage $N$ (Normal), response in or above the reference area; Stage sL (subnormal Level), subnormal 2-h cortisol level with normal 2-h increment; Stage sLI (subnormal Level and Increment), subnormal 2-h cortisol level with subnormal but significant 2-h increment; Stage sLaI (subnormal Level, absent Increment); and Stage R, (Replacement therapy), comprises all patients with cortisol substitution.

\section{RESULTS}

Individual follow-up by 2 hAT (Table 2 and Fig. 1). Of the 17 patients initially in stage $\mathrm{N}$, four were still in that stage at the end of the study. None of these four patients had antibodies. In

Table 2. Frequencies of different changes (including no change) in the stage of cortisol secretory capacity between two consecutive 2 hATs in patients with APECED

\begin{tabular}{lrrrcc}
\hline & \multicolumn{5}{c}{ Stage in the following 2hAT } \\
\cline { 2 - 6 } stage ${ }^{\text {in }}$ in the \\
preceding 2hAT & $\mathrm{N}$ & $\mathrm{sL}$ & $\mathrm{sLI}$ & sLaI & $\mathrm{R}$ \\
\hline $\mathrm{N}$ & 59 & 11 & 8 & 1 & 0 \\
SL & 4 & 3 & 3 & 1 & 0 \\
SLI & 1 & 1 & 3 & 6 & 2 \\
SLaI & 0 & 0 & 3 & 3 & 3 \\
R & 0 & 0 & 0 & 0 & 1 \\
\hline
\end{tabular}

${ }^{1}$ For the definition of stage $(\mathrm{N}, \mathrm{sL}, \mathrm{sLI}, \mathrm{sLaI}, \mathrm{R})$, see footnote in $\mathrm{Ta}-$ ble 1.
16 patients, 13 with a normal and three with a subnormal initial result, the response had deteriorated.

Between two consecutive tests there was no change of stage in 69 instances. A "deterioration" had occurred in 35 pairs and an "improvement" in nine pairs.

The first subnormal stage observed after stage $\mathrm{N}$ was stage sL in 11 patients, stage sLI in eight patients and stage sLaI in one patient (after an interval of 1.6 years).

Subnormal basal levels were observed in only three out of 20 patients in stage sLal with advanced disease, but in 11 out of 15 patients in stage $R$. After a result from stage-sL, the next result was of the same stage three times, and of a poorer stage four times, but normal four times. After a stage-sLI result the next result was of the same stage three times, of a poorer stage eight times, but of a better stage twice, there being a normal finding once. Only after stage sLal had shown up in one result were subsequent findings always abnormal, even though a significant increment appeared three times.

The mean interval from the last stage- $\mathrm{N}$ result was, to stage sL $1.1 \pm 0.2$ (S.E.M.; range, $0.2-2.3$ ) years, to stage sLI $1.6 \pm 0.2$ $(0.7-2.4)$ years, and to stage sLaI $2.6 \pm 0.3(1.6-3.8)$ years. The mean interval from the first subnormal finding to stage sLal was $1.0 \pm 0.3(0.3-1.5)$ years. Because of the testing frequency, some of these intervals are overestimated.

"Improvements" in stage between consecutive tests could often be attributed to normal intra-individual variation of response. In a least two patients (Fig. $1 \mathrm{G}-\mathrm{H}$ ) there appeared to be a real improvement in cortisol secretory capacity. Both patients had antibodies while in stage N. Both developed clear failure.

Primed 2-h ACTH test. Of the 27 tests performed, 11 were in stage-N patients. Reference ranges calculated from their results were the following: "basal" cortisol level, $18-108 \mu \mathrm{g} / \mathrm{dl}(0.50-3.0$ $\mu \mathrm{M}) ; 2$-h level $31-111 \mu \mathrm{g} / \mathrm{dl}(0.86-3.1 \mu \mathrm{M})$; and 2-h increment
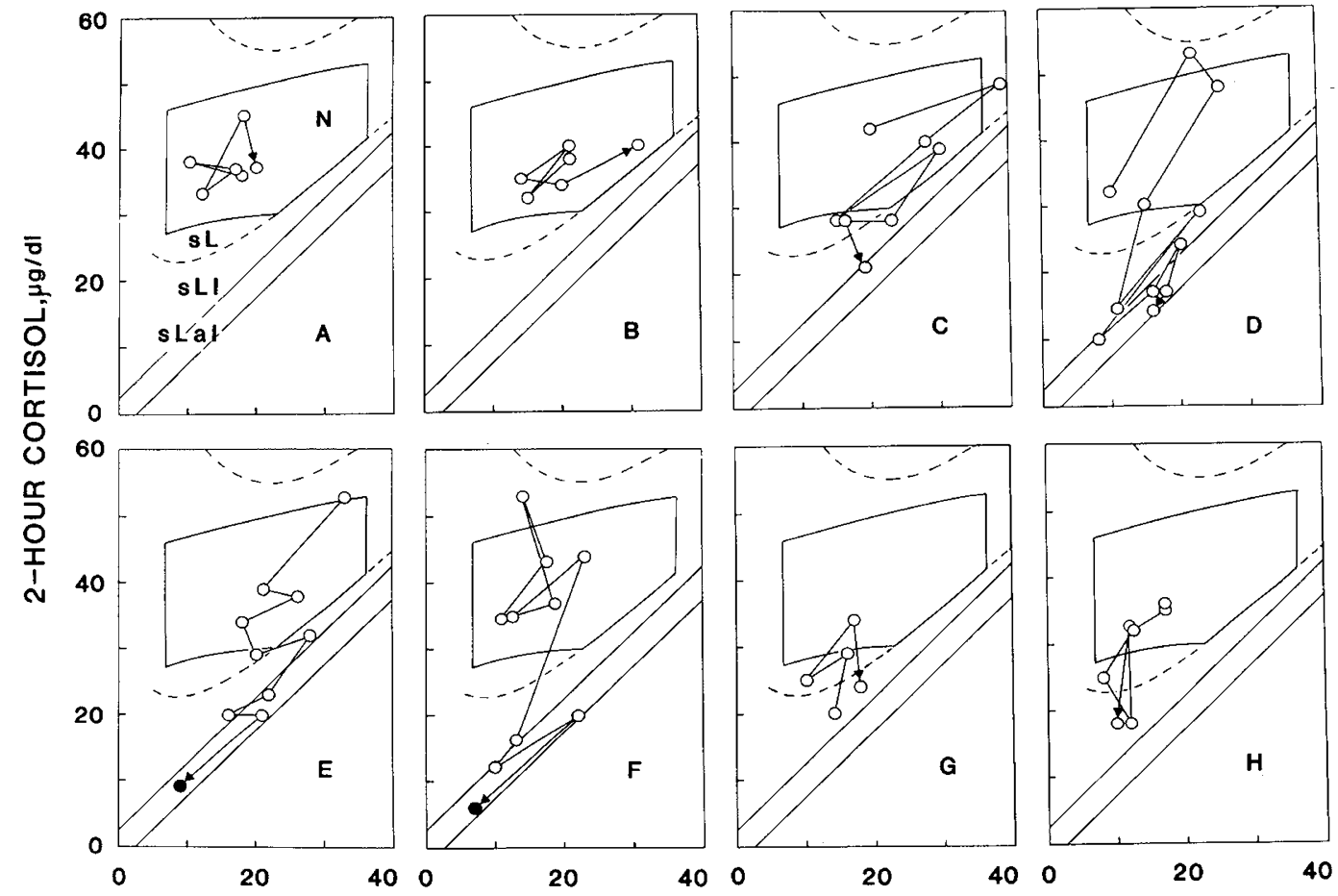

BASAL CORTISOL, $\mu g / d I$

Fig. 1. Follow-up of eight patients with APECED by the 2hAT. The pentagon is the normal response area formed by the $95 \%$ confidence limits for basal (vertical borders) and 2-h (parallel upper and lower borders) plasma cortisol levels, and (in the lower right corner) by the $95 \%$ confidence limit for the 2-h increment. The upper and lower borders are curved because of conversion of log scale to linear scale. Interrupted lines indicate the continuation of the $95 \%$ confidence limits for the increment. The two diagonals starting from the lower left corner indicate the zone in which the 2-h level equals the basal level within the precision of the method. The response areas for three stages of failure of cortisol secretory capacity are indicated in panel $A$ by the symbols of these stages sL, sLI, sLaI, see footnote in Table 1. Each result is indicated by $O$ (no previous cortisol substitution) or (during cortisol substitution). The sequence of the tests is indicated by the connecting line with an arrow pointing to the last test. 

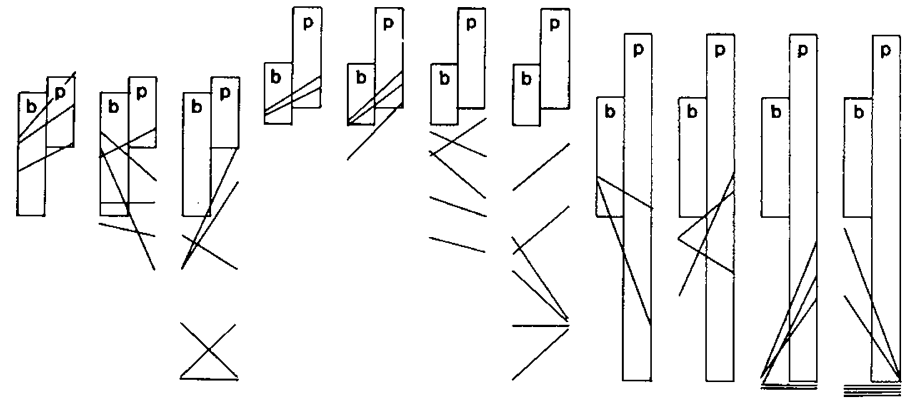

sL $\quad$ sLI sLal

R $\quad s L$

sLI sLal

R

sL

LI sLal

$\mathbf{R}$

Fig. 2. Results of the $2 \mathrm{hAT}$ and primed $2 \mathrm{hAT}$ in patients with APECED. The columns indicate the $95 \%$ confidence ranges in the (basal) $2 \mathrm{hAT}$ $(b)$ and primed $2 \mathrm{hAT}(p)$ for the basal plasma cortisol (left panel), 2-h cortisol (middle panel), and 2-h increment (right panel). The lines indicate the values in individual patients, grouped according to stage of cortisol secretory capacity (N, sL, sLaI, and R, see footnote in Table 1). The ranges were calculated from the findings in stage- $\mathrm{N}$ patients; therefore, for the $2 \mathrm{hAT}$ they differ from the ranges of healthy children.

$1-80 \mu \mathrm{g} / \mathrm{dl}(0.03-2.2 \mu \mathrm{M})$. Of five tests in stage-sL or sLI patients all gave normal responses according to the criteria for both the 2hAT and primed $2 \mathrm{hAT}$ (Fig. 2). Of the five stage sLaI patients, in contrast, none gave a normal response; however, a significant increment now appeared in three. In six tests on stage- $R$ patients, four showed no change from the basal 2hAT; in one test an increase appeared in the "basal" level, and in another the increment disappeared.

4-Dav ACTH test. Nine of the 264 dATs performed were in stage- $\mathrm{N}$ patients (see Fig. 3 for the reference ranges obtained from their values). Six of the tests were in stage-sL or sLI patients; all responses were normal (Fig. 3). In contrast, all five sLal patients responded subnormally. All three patients with subnormal basal 17-OGS showed a significant increment in 17-OGS. This appeared during the first day in ACTH in one patient and during the second day in two patients. In all three the value then fell in spite of continuing ACTH stimulation. In the six stage-R patients responses were variable. Four of them had a significant increment in 17-OGS, one of them an almost normalized level during the third day on ACTH (Fig. 3).

Plasma ACTH concentrations (Table 3 and Fig. 4). Several patients in stage- $\mathrm{N}$, but with antibodies, had elevated ACTH levels. In contrast, all stage- $\mathrm{N}$ patients without antibodies had normal levels. Both the proportion of levels that were elevated and the mean level increased parallel to the stage of failure. The mean level for the stage was not significantly elevated until stage sLI. Institution of cortisol replacement therapy led to an expected decrease in the mean ACTH level.

Cortisol/ACTH molar ratios (Table 3 and Fig. 4). In stage-N patients without antibodies the range of the molar ratios was 25$136 \times 10^{3}$. In all patients with elevated plasma ACTH levels the ratio was below this range. The proportion of ratios that were subnormal $\left(<20 \times 10^{3}\right)$ increased and the mean ratio decreased parallel to the stage of failure. Even at stage sL the mean ratio for the stage was significantly below the value of stage- $\mathrm{N}$ without antibodies.

Insulin and vasopressin tests. These tests were given to some of the patients in efforts to study the endogenous ACTH reserve. The plasma cortisol increments found in these tests were similar in magnitude to those induced by exogenous ACTH in the 2hAT (Fig. 5). Surprisingly, in the vasopressin test significant increments were observed in some stage-sLaI patients. Only in stage $\mathrm{R}$ was an $\mathrm{ACTH}$ reserve never detectable.

2hAT in hypocortisolism: APECED versus hypopituitarism. Before the start of cortisol substitution in the patients with APECED, a significant increment was observed in only 26 of the 46 2hATs; eight of these increments were normal (Fig. 6). In the patients with hypopituitarism, in contrast, all 13 tests showed a significant increment, and seven of the increments were normal. The absence of an increment strongly suggests primarily hypo-

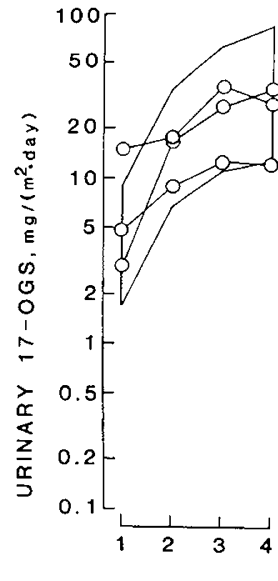

sL
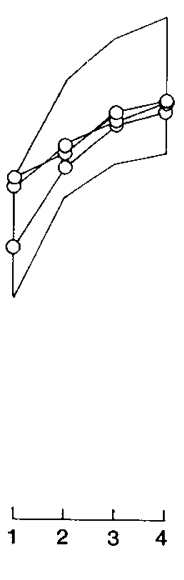

$s L I$
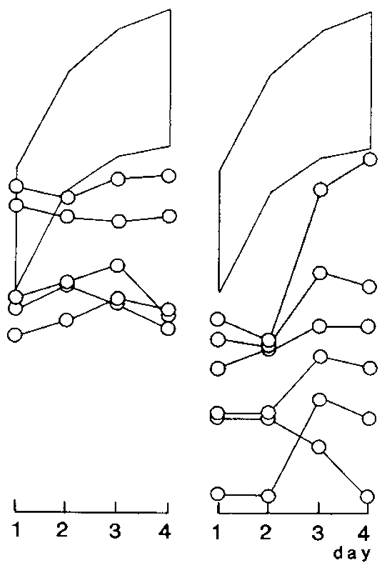

R
Fig. 3. Results of the 4dAT in patients with APECED. The polygons indicate the $95 \%$ confidence limits of the results in patients with a normal finding (stage-N) in the $2 \mathrm{hAT}$. The sequence of interconnected circles indicate the results for individual patients, grouped according to their stages of cortisol secetory capacity (sL, sLI, sLaI; and R, see footnote in Table 1.

cortisolism. But in patients with subnormal 2-h cortisol levels the presence of a significant, even normal, increment in $2 \mathrm{hAT}$ does not exclude primary hypocortisolism or establish secondary hypocortisolism.

The pattern of plots for the patients with increments suggests that for a given basal cortisol level the increment is larger in secondary than in primary hypocortisolism (Fig. 6). Accordingly, both the increment/basal level ratio and the 2 -h level/basal level ratio were lower $(P<0.001)$ in APECED $(0.43 \pm 14 \%$ and 1.50 $\pm 5 \%$, respectively) than in hypopituitarism $(1.14 \pm 27 \%, 2.32$ $\pm 13 \%$ ). Only three of the 27 ratios in patients with APECED were below the hypopituitary range.

During cortisol substitution a different picture emerged (Fig. 6). Now a significant increment was observed in only one of 16 2hATs in patients with APECED, in contrast to 17 of 21 tests in patients with hypopituitarism. A significant increment during cortisol substitution strongly suggests secondary hypocortisolism, but absence of an increment does not exclude secondary or establish primary hypocortisolism.

\section{DISCUSSION}

In patients with autoimmune adrenalitis, replacement of cortical cells by fibrous tissue and lymphocytic infiltration of the remaining islets of cortical cells eventually lead to primary 
adrenocortical failure (9). These patients often have circulating adrenocortical antibodies $(3,9,20)$. We have followed the gradual development of hypocortisolism in a group of patients with the adrenalitis of APECED, a disease progressing to adrenocortical failure in about two-thirds of the patients (23). During progression of the failure in these patients we frequently observed patterns of response in ACTH tests which were in conflict with the established diagnostic criteria of primary hypocortisolism (1, $8,16,19,31$; see below). In this report we suggest new criteria for diagnosing and staging primary hypocortisolism by a 2-h ACTH tests. The evidence needed to characterize the state of the adrenal cortex also includes information about plasma $\mathrm{ACTH}$ concentrations and the presence of antibodies.

The diagnosis is currently based on two criteria. First, in response to exogenous $\mathrm{ACTH}$ an increment in urinary steroids

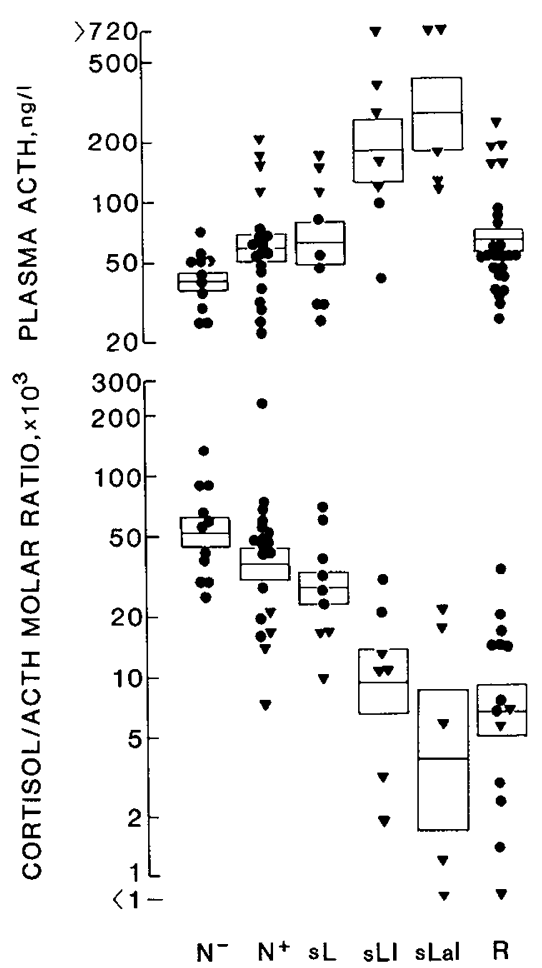

Fig. 4. Basal plasma ACTH levels (upper panel) and cortisol/ACTH molar ratios (low'er panel) in patients with APECED grouped according to stage of cortisol secretory capacity $(\mathrm{N}, \mathrm{sL}$, sLI, sLal; and $\mathrm{R}$, see footnote in Table 1. Stage- $N$ (normal response) was divided according to the absence $\left(\mathrm{N}^{-}\right)$or presence $\left(\mathrm{N}^{+}\right)$of antibodies. Symbols: $\bullet$ ACTH $<100 \mathrm{ng} / \mathrm{l}$ liter; $\mathbf{\Lambda}$. ACTH $>100 \mathrm{ng} /$ liter. The columns indicate the means and S.E.M.s. Three ACTH levels were $>720 \mathrm{ng} / \mathrm{liter}$, but the corresponding ratios were calculated using $720 \mathrm{ng} / \mathrm{liter}$; these ratios are therefore underestimated. and plasma cortisol level should be absent. Even a small slow increase has been accepted as adequate evidence of the secondary nature of the hypocortisolism $(1,8,16,19,31)$. Second, especially when plasma cortisol levels are low, plasma ACTH concentrations should be elevated $(2,24)$. We found that, during the development of hypocortisolism, the absence of an ACTH-induced increment in plasma or urinary steroids was a late feature, often preceded by years of slow progressive decline in the other parameters of cortisol secretory capacity. We have defined the criteria for the result of the $2 \mathrm{hAT}$ by a novel analysis (13) of the results in healthy children. Basal and $2-h$ cortisol levels show no intra-individual dependence and are thus independent measures of cortisol secretory capacity. In contrast, the increment is totally dependent on the intra-individual variations in the basal and 2$\mathrm{h}$ levels; hence, the increment should not be taken as the sole parameter of the test result (13). Surprisingly, we observed subnormal basal cortisol levels in only a few patients with far

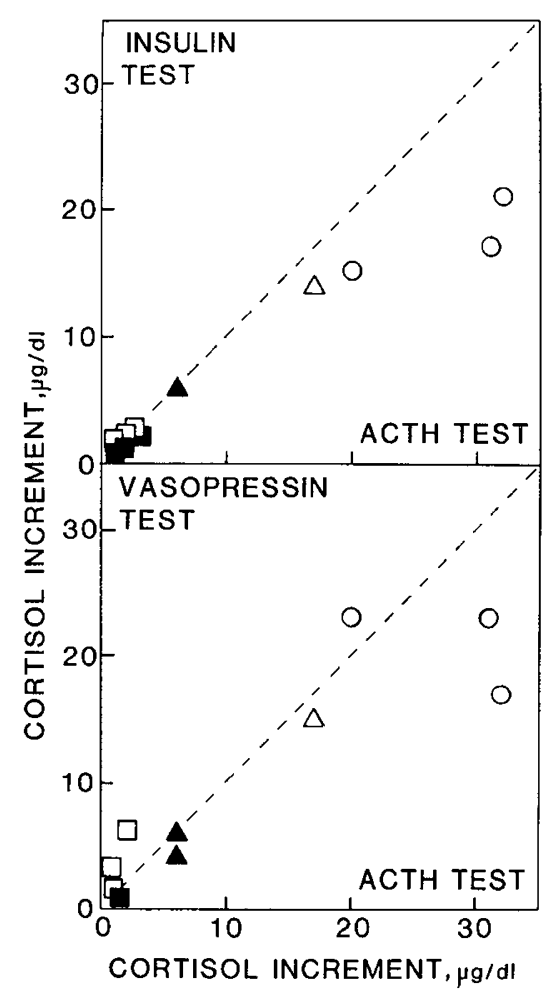

Fig. 5. The plasma cortisol increments of APECED patients in the insulin test (upper panel) and vasopressin test (lower panel) against their increments in the contemporaneous $2 \mathrm{hAT}$. The interrupted line is the line of identity of response. The symbols indicate the stages of cortisol secretory capacity (see footnote in Table 1 ): $\mathrm{O}, \mathrm{N} ; \triangle, \mathrm{sL} ; \boldsymbol{\Delta}$, sLI; $\square$, sLaI; a, R.

Table 3. Plasma ACTH levels and cortisol/ACTH molar ratios in basal blood of patients with APECED

\begin{tabular}{|c|c|c|c|c|c|c|}
\hline \multirow{3}{*}{$\begin{array}{c}\begin{array}{c}\text { Stage of cortisol } \\
\text { secretory capacity }\end{array} \\
\mathrm{N}^{-}\end{array}$} & \multicolumn{3}{|c|}{ Plasma ACTH } & \multicolumn{3}{|c|}{ Cortisol/ACTH molar ratio } \\
\hline & \multicolumn{2}{|c|}{$\begin{array}{l}\text { Mean level, ng/liter } \\
\text { (S.E.M., \%) }\end{array}$} & \multirow{2}{*}{$\begin{array}{l}\begin{array}{l}\text { Proportion of patients with } \\
\text { plasma ACTH }>100 \mathrm{ng} / \mathrm{liter}\end{array} \\
0 / 11\end{array}$} & \multicolumn{2}{|c|}{$\begin{array}{c}\text { Mean ratio } \times 10^{3} \\
(\text { S.E.M., \%) }\end{array}$} & \multirow{2}{*}{$\begin{array}{l}\text { Proportion of patients with ratio } \\
<20 \times 10^{3}\end{array}$} \\
\hline & 40 & $(10)$ & & 53.0 & $(18)$ & \\
\hline $\mathrm{N}^{+}$ & 58 & (15) & $4 / 19$ & 36.8 & (19) & $3 / 19$ \\
\hline sL & 61 & (26) & $3 / 9$ & $27.9^{2}$ & (23) & $3 / 9$ \\
\hline sLI & $175^{2}$ & (43) & $5 / 7$ & $9.4^{2}$ & (45) & $5 / 7$ \\
\hline sLaI & $263^{2.3}$ & $(52)$ & $5 / 5$ & $3.8^{2.3}$ & $(127)$ & $4 / 5$ \\
\hline $\mathrm{R}$ & $62^{2}$ & (13) & $5 / 25$ & $6.8^{2}$ & (34) & $12 / 14$ \\
\hline
\end{tabular}

\footnotetext{
' Superscripts $(-)$ and $(+)$ indicate absence and presence of antibodies. For the definition of stages (N, sL, sLI, sLal, R), see footnote in Table 1 .

${ }^{2}$ Significantly $(P<0.05)$ different from the value of stage $\mathrm{N}^{-}$.

${ }^{3}$ In three of five samples the ACTH concentration was above the measured range ( $>720 \mathrm{ng} / \mathrm{liter}$ ), but was taken as $720 \mathrm{ng} / \mathrm{liter}$ in the calculations; therefore, the mean is underestimated and the molar ratio overestimated.
} 
advanced disease, presumably long after total depletion of cortisol reserves. An appropriate staging of the responses was obtained by using two parameters in parallel, the 2-h level and the 2-h increment. Because of the inter-individual dependence of both of these on the basal level, the evaluation is best done on a plot of 2 -h level versus basal level (13). As shown by these criteria, the first stage of failing cortisol secretory capacity was a subnormal 2-h level, alone or with a subnormal increment. The urinary 17-OGS response in the 4dAT remained normal as long as there was a significant increment in the $2 \mathrm{hAT}$. A significant response was maintained longer in the $4 \mathrm{dAT}$ than in the $2 \mathrm{hAT}$. The $4 \mathrm{dAT}$ was thus clearly not sufficiently sensitive to detect incipient or moderate failure of cortisol secretory capacity.

In accordance with our findings, several groups have observed significant responses in plasma and urinary steroids in patients with primary adrenocortical failure. Progression of the failure has also been demonstrated by some authors. In patients with adrenal remnants after subtotal adrenalectomy, increments in both urinary and plasma steroids were only slightly subnormal after 2-3 days infusion of ACTH $(10,26)$ or in a 60 -min ACTH test (10). A response was also obtained in a patient with adrenal calcification (27). Six patients with mild Addison's disease showed near-normal increments in urinary steroids after ACTH infusion (7). A child with Addison's disease responded with a 3fold increase in urinary 17-hydroxycorticosteroids after 3 days on ACTH gel (5). Adults with the primary adrenocortical failure of Schmidt's (21) and Chiari-Frommel's (25) syndromes showed prompt increases in urinary plasma steroids in ACTH tests. Similar increases have been observed in two patients with adrenoleukodystrophy or adrenomyeloneuropathy (6) and in three

NO PREVIOUS CORTISOL CORTISOL SUBSTITUTION

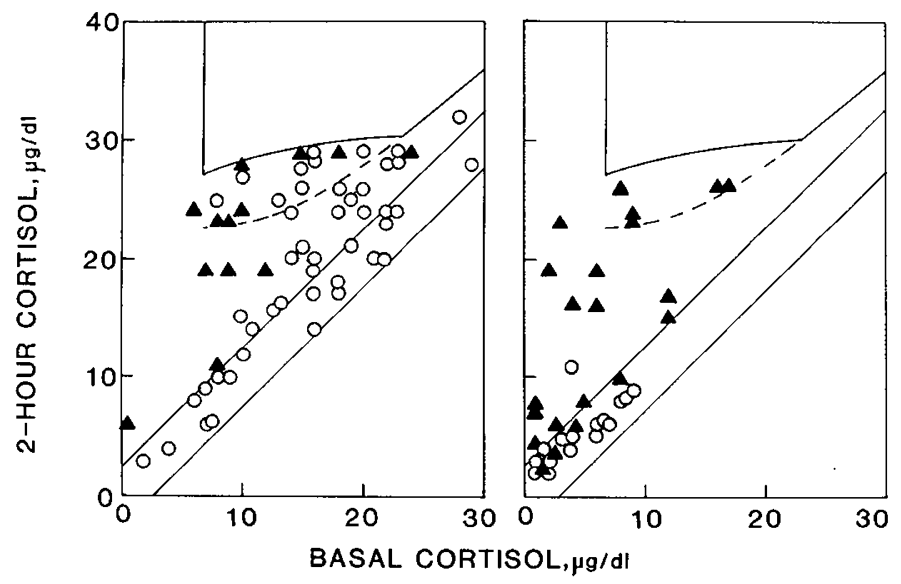

Fig. 6. Comparison of all subnormal $2 \mathrm{hAT}$ results in patients with APECED or hypopituitarism. Patients without previous cortisol substitution, left panel; patients with cortisol substitution, right panel. The normal response area (see Fig. 1) is only partially shown. Symbols: O, APECED; $\mathbf{\Lambda}$, hypopituitarism. children with the "syndrome of familial glucocorticoid insufficiency" $(17,29)$. During follow-up several of these patients primary adrenocortical failure clearly advanced to absence of an ACTH-induced response $(7,17,29)$. Clearly, the finding of a significant and even normal steroid increment in an ACTH test is not an acceptable criterion for exclusion of primary adrenocortical failure.

As the failure progressed we found an increasing proportion of elevated plasma ACTH levels. Only in patients in whom the $2 \mathrm{hAT}$ no longer induced any increment was the ACTH level constantly elevated. Elevated ACTH levels were invariably associated with a subnormal cortisol/ACTH molar ratio and vice versa except among the cortisol-substituted patients, who had subnormal ratios even when ACTH levels were normal. The molar ratio was no more sensitive than the ACTH level as an indicator of the disease, and usually less sensitive than the $2 \mathrm{hAT}$. A normal plasma ACTH level and a normal cortisol/ACTH ratio definitely do not exclude primary adrenocortical failure.

In some patients in whom $2 \mathrm{hAT}$ results were normal, ACTH levels were elevated. These patients had antibodies and their cortisol/ACTH ratios were low, indicating incipient adrenocortical failure. They later developed hypocortisolism. High ACTH levels have been reported previously in a patient whose steroid response to ACTH was only slightly subnormal (21). We suggest that such patients have a compensatory activation of the hypothalamic-pituitary-adrenocortical axis, a notion that is supported by two lines of evidence. First, a prolonged normalization of the $2 \mathrm{hAT}$ was observed in two of our patients with antibodies, both of whom later developed hypocortisolism. Such partial recovery has also been reported in a patient with South American blastomycosis (22). Second, in patients with incipient or moderate hypocortisolism the results of primed $2 \mathrm{hAT}$ were in the normal range. That these patients still have an endogenous reserve of ACTH is proved by the significant cortisol responses to the insulin and vasopressin tests. In conclusion, staging of failing cortisol secretory capacity cannot be based solely on the responses to the ACTH tests. Long lasting ACTH tests are clearly not sensitive enough for detection of early stages, and a normal response to $2 \mathrm{hAT}$ does not exclude a lesion. Determinations of plasma ACTH and adrenal antibodies are also needed.

Differentiaton with ACTH tests between patients with primary and secondary hypocortisolism was possible only in specified situations. First, in patients with no cortisol substitution an absent increment in the $2 \mathrm{hAT}$ strongly suggested primary hypocortisolism. Second, in patients on cortisol substitution the presence of an increment strongly suggested secondary hypocortisolism. Because even those patients with advanced hypocortisolism gave normal or only slightly subnormal responses in the 4dAT and the primed $2 \mathrm{hAT}$, long lasting ACTH tests appear clearly inappropriate for the differentiation in all but very advanced cases of hypocortisolism. Furthermore, hypopituitary patients with subnormal plasma cortisol response in insulin test often gave normal response in ACTH tests $(4,13)$. The differentiation must be based on the clinical picture, and on other tests of pituitary function.

Table 4. Apparent developmental sequerue of hypocortisolism in adrenalitis of APECED

\begin{tabular}{|c|c|c|c|c|c|c|c|}
\hline & $\begin{array}{c}\text { Basal plasma } \\
\text { cortisol }\end{array}$ & $2 \mathrm{hAT}$ & $\begin{array}{c}\text { Primed } \\
2 \mathrm{hAT} \\
\end{array}$ & $4 \mathrm{dAT}$ & $\begin{array}{l}\text { Plasma } \\
\text { ACTH }\end{array}$ & $\begin{array}{c}\text { Cortisol/ACTH } \\
\text { ratio } \\
\end{array}$ & $\begin{array}{c}\text { Adrenocortical } \\
\text { antibodies }\end{array}$ \\
\hline No adrenalitis & $\mathrm{N}^{1}$ & $\mathrm{~N}$ & $N$ & $\mathrm{~N}$ & $\mathrm{~N}$ & $\mathrm{~N}$ & - \\
\hline Start of adrenalitis & $\mathrm{N}$ & $\mathrm{N}$ & $\mathrm{N}$ & $\mathrm{N}$ & $\mathrm{N}$ & $\mathrm{N}$ & + \\
\hline $\begin{array}{l}\text { Partly destroyed adrenal } \\
\text { gland }\end{array}$ & $N$ & $\mathrm{sL} / \mathrm{sLI}$ & $\mathrm{N}$ & $\mathrm{N}$ & $\mathrm{N}$ & $\mathrm{N}$ & + \\
\hline $\begin{array}{l}\text { Compensatory increase in } \\
\text { ACTH secretion }\end{array}$ & $\mathrm{N}$ & $\mathrm{N}$ & $\mathrm{N}$ & $\mathrm{N}$ & increased & decreased & + \\
\hline $\begin{array}{l}\text { Further destruction of adre- } \\
\text { nal remnant }\end{array}$ & $\mathrm{N} /$ decreased & $\mathrm{sL} / \mathrm{sLI} / \mathrm{sLaI}$ & $\mathrm{N} / \mathrm{sLI} / \mathrm{sLaI}$ & $\mathrm{N} / \mathrm{sLI} / \mathrm{sLal}$ & $\begin{array}{l}\text { further in- } \\
\text { creased }\end{array}$ & further decreased & $+1-$ \\
\hline During cortisol substitution & decreased & sLaI & sLaI & sLaI & $\mathrm{N}$ & decreased & $+1-$ \\
\hline
\end{tabular}

\footnotetext{
'For the definition of stages (N, sL, sLI, sLaI, R), see footnote in Table 1.
} 
The pathogenetic role of circulating adrenocortical antibodies is unclear. We tested for antibodies in our patients too infrequently to allow conclusions about their constant association or otherwise with the adrenalitis of APECED. Antibodies were not observed in any of those of our patients who did not develop hypocortisolism. They were present in all patients who, despite normal $2 \mathrm{hAT}$ results, had elevated plasma ACTH levels and low cortisol/ACTH ratios, presumably indicating an active adrenal lesion. Testing for the antibodies thus appeared positively and negatively predictive of the development of hypocortisolism. The apparent sequence of development of hypocortisolism in APECED is summarized in Table 4.

\section{REFERENCES AND NOTES}

1. Baxter J. D. and Tyrrell J. B. The Adrenal Cortex In: P. Felig J.D. Baxter. A.E. Broadus, L.A. Frohman: Endocrinology and Metabolism. p. 385-510 (McGraw-Hill, New York, 1981).

2. Besser, G. M.. Cullen, D. R., Irvine, W. J., Ratcliffe, J. G., and Landon, J.: Immunoreactive corticotrophin levels in adrenocortical insufficiency. Br. Med. J.. I: 374 (1971):

3. Blizzard, R. M., Chee, D., and Davis, W. The incidence of adrenal and other antibodies in the sera of patients with idiopathic adrenal insufficiency (Addison's disease). Clin. Exp. Immunol., 2: 19 (1967).

4. Borst, G. C.. Michenfelder, H. J., and O'Brien, J. T.: Discordant cortisol response to exogenous ACTH and insulin-induced hypoglycemia in patients with pituitary disease. N. Engl. J. Med., 306: 1462 (1982).

5. D'albora, J. B. and Martin, M. M.: Addison's disease in childhood. Report of two cases. Am. J. Dis. Child., 111:208 (1966).

6. Davis, L. E.. Snyder, R. D., Orth, D. N.. Nicholson, W. E., Kornfeld, M. and Seelinger, D. F.: Adrenoleukodystrophy and adrenomyeloneuropathy associated with partial adrenal insufficiency in three generations of a kindred. Am. J. Med., 66: 342 (1979).

7. Heni. F., Göbel, P., and Mast. H.: Hormontests in der Diagnostik des Morbus Addison: Hormonausscheidung (Porter-Silber-Chromogene, 17-Ketosteroide. Dehydroepiandrosteron) und i.v. ACTH-Test in der Diagnostik des Morbus Addison. Dtsch. Med. Wochenschr., 83: 1928 (1958).

8. Irvine. W. J. and Barnes, E. W.: Adrenocortical insufficiency. Clin. Endocrinol. Metab., 1: 549 (1972)

9. Irvine, W. J. and Barnes, E. W.: Addison's disease, ovarian failure and hypoparathyroidism. Clin. Endocrinol. Metab. 4: 379 (1975).

10. Knappe, G. and Stahl. F.: Prüfung der Nebennierenrindenfunktion mit intravenösen ACTH-Injektion und fluorometrischer Bestimmung der Plasmakortikosteroide. Das deutsche Gesundheitswesen, 19:822 (1964).

11. Krohn. K.. Perheentupa, J., and Heinonen, E.: Precipitating anti-adrenal antibodies in Addison's disease. Clin. Immunol. Immunopathol.. 3: 59 (1974).

12. Leisti, S., and Perheentupa. J.: Critical evaluation of the 5-day metyrapone test. Hormone Res. (Basel). 8: 1 (1977).

13. Leisti, S. and Perheentupa, J.: Two-hour adrenocorticotropic hormone test: Accuracy in the evaluation of the hypothalamic-pituitary-adrenocortical axis.
Pediatr. Res., 12: 272 (1978)

14. Leisti, S. and Perheentupa, J.: Insulin test: precisions of and correlations between glucose and hormone responses. Acta Endocrinol., 88: 99 (1978).

15. Leisti. S. and Perheentupa, J.: Vasopressin test: Diagnostic inaccuracy in evaluation of hypothalamic-pituitary-adrenocortical axis. Acta Endocrinol.. 87: 28 (1978).

16. Liddle, G. W. The adrenal cortex. In: R.H. Williams. Textbook of Endocrinology. 6th Ed. p. 249-292 (W.B. Saunders Co, Philadephia, 1981).

17. Moshang. T., Rosenfield, R. L., Bongiovanni, A. M., Parks, J. S., and Asurhein. J. A.: Familial glucocorticoid insufficiency. J. Pediatr., 82: 821 (1973).

8. Myllärniemi. S. and Perheentupa. J.: Oral findings in the autoimmune polyendocrinopathy-candidosis syndrome (APECS) and other forms of hypoparathyroidism. Oral Surg. Oral Med. Oral Pathol., 45: 721 (1978).

19. Müller, J.: Untersuchungsmethoden der Nebennierenrinden-Funktion. In: A. Labhart, Klinik der Inneren Sekretion. 3rd Ed. p. 385-422 (Springer Verlag, 1978).

20. Nerup. J.: Addison's disease-serological studies. Acta Endocrinol., 76: 142 (1974).

21. Nicholls, M. G.. Espiner. E. A., and Donald. R. A.: Schmidt's syndrome presenting as hypopituitarism. Ann. Intern. Med., 80: 505 (1974).

22. Osa, S. R., Peterson, R. E., and Roberts, R. D.: Recovery of adrenal reserve following treatment of disseminated South American blastomycosis. Am. J. Med., 71: 298 (1981).

23. Perheentupa J : Autoimmune polyendocrinopathy-candidosis-ectodermal dystrophy (APECED). In: A.W. Erikson, H.R. Forsius, H.R. Nevanlinna, P.L. Workman, R.K. Norio. Population structure and genetic disorders. p. 583587 (Academic Press. London, 1980).

24. Rees. L. H.: ACTH, lipotrophin and MSH in health and disease. Clin. Endocrinol. Metab.. 6: 137 (1977).

25. Refetoff, S.. Block. M. B.. Ehrlich, E. N.. and Friesen, H. G.: Chiari-Frommel syndrome in a patient with primary adrenocortical insufficiency. Cure by glucocorticoid replacement. N. Engl. J. Med., 287: 1326 (1972)

26. Rose. L. J.. Williams. G. H.. Jagger. P. L., and Lauler, D. P.: The 48-hour adrenocorticotrophin infusion test for adrenocortical insufficiency. Ann. Intern. Med.. 73: 49 (1970)

27. Sandberg. A. A. Eik-Nes, K, and Migeon, C. J.: Plasma 17-hydroxycorticosteroids in hyperfunction. suppression and deficiency of adrenal cortical function. J. Lab. Clin. Med.. 50: 286 (1957).

28. Snedecor, G. W. and Cochran. W. G.: Statistical Methods. 7th Ed. 291. (The Iowa State University Press. Iowa. 1980).

29. Stempfel, R. S and Engel, F. L.: A congenital, familial syndrome of adrenocortical insufficiency without hypoaldosteronism. J. Pediatr.. 57: 443 (1960).

30. Thomas, B. S.: Comparison between sodium meta-periodate and sodium bismuthate methods for the determinations of urinary 17-ketogenic steroids. J Clin. Endocrinol. Metab. 25:710 (1965).

31. West. C.D. and Meikle, A. W.: Laboratory tests for the diagnosis of Cushing's syndrome and adrenal insufficiency and factors affecting those test. In: L.J. Degroot, G.F. Cahill, L. Martini. D.H. Nelson, W.D. Odell, J.T. Potts, A.I. Winegrad: Endocrinology. Vol. 2. p. 1157-1177. Grune \& Stratton, New York, 1979).

32. Requests for reprints should be addressed to: S. Leisti, M.D., Children's Hospital, SF-00290 Helsinki 29. Finland.

33. Received for publication July 12, 1982.

34. Accepted for publication April 5, 1983. 